\title{
Repercussões Psicossociais da Depressão no Contexto da Aids
}

Pyschosocial repercussions of depression in the context of aids

Alessandra Ramos Castanha, Maria da Penha de Lima Coutinho, Ana Alayde Werba Saldanha \& Cristiane Galvão Ribeiro

Universidade Federal da Paraíba 


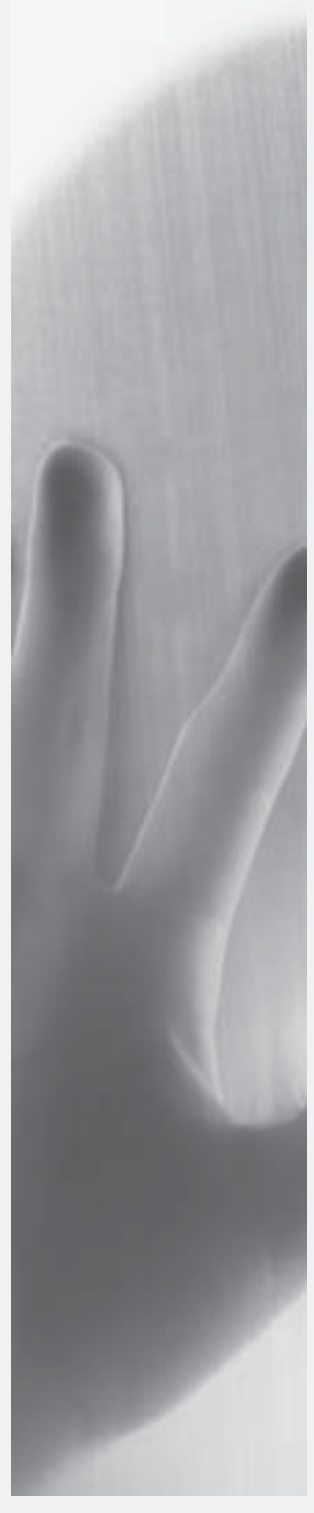

Resumo: A Aids é, freqüentemente, associada a transtornos psiquiátricos, sendo a depressão o mais comum deles. Esta pesquisa teve como objetivos: 1) apreender as representações sociais da Aids e da depressão por soropositivos para o HIV; 2) avaliar a prevalência da sintomatologia da depressão. Participaram deste estudo 91 sujeitos soropositivos, de ambos os sexos, com média de idade de 38 anos. Foram utilizados, como instrumentos, o Teste de Associação Livre de Palavras e o inventário de Beck para medir depressão. Os dados obtidos possibilitaram representações da depressão e da Aids como uma doença que atinge o ser humano em sua globalidade, repercutindo em vários aspectos de sua vida, tais como na qualidade de vida, na produtividade e na capacitação social. A prevalência da sintomatologia depressiva encontrada neste estudo (64\%) remete à necessidade do preparo dos profissionais para diagnosticarem e tratarem esse fenômeno dentro do contexto da Aids.

Palavras-chave: repercussões psicossociais, depressão, Aids.

Abstract: AIDS is frequently associated with psychiatric disturbs, being depression the most common of those. This research has as objectives: 1) seize the social representations of AIDS and depression by HIV serumpositive persons; 2) evaluate the prevalence of depression's symptoms. Ninety-one HIV serum-positive persons participated in this research. They were of both genders, with mean age of 38 years. The Test of Free Association of Words and Beck's inventory to measure were used as instruments. The data obtained made it possible to represent depression and AIDS as a disease that reach the human being in their totality, with repercussions in several aspects of their lives, such as quality of life, productivity, and social capacitation. The prevalence of depression symptoms found in this study (64\%) show the necessity of capacitating professionals for the diagnosis and treatment of this phenomenon within the context of AIDS.

Key words: pyschosocial repercussions, depression, AIDS.

A depressão ocorre, muitas vezes, concomitantemente a uma doença clínica, podendo ser uma complicação da doença (ou de seu tratamento), a sua causa ou mera coincidência de caso; em geral, trata-se de uma relação altamente complexa, algumas vezes mal-interpretada e, freqüentemente, negligenciada. A depressão é o mais comum dos distúrbios psicológicos associados à doença clínica e é, ao mesmo tempo, não detectada e/ou não tratada (Brasil, 1999).
Esse fenômeno ocorre com a Aids, freqüentemente associada a transtornos psiquiátricos, sendo o mais comum deles a depressão, podendo-se observar uma porcentagem de 11 a 30\% de prevalência de transtornos depressivos nos portadores da infecção (Rodin; Craven; Littlefield, 1991). O diagnóstico e o tratamento desses transtornos são fundamentais para melhorar a qualidade de vida dos pacientes; no entanto, 50 a 60\% dos casos de depressão não são diagnosticados 
(Malbergier, 2000). Observam-se, aqui, dois dados alarmantes. Por um lado, está o alto índice de prevalência da depressão, e, por outro, o baixo número de casos diagnosticados.

A avaliação de depressão é difícil devido à fronteira imprecisa e, às vezes, arbitrária, entre as formas clínicas, subclínicas e as nãopatológicas. Essa dificuldade atinge o seu ápice quando se trata de um paciente com doença clínica. Nesse caso, as distinções se tornam ainda mais problemáticas, porque há uma base real para o sentimento de tristeza associado a uma doença clínica grave e porque sintomas somáticos, tais como anorexia ou perda de energia, podem ser decorrentes da doença clínica (Brasil,1999).

A depressão, maior em pacientes soropositivos, está associada a vários fatores: (1) impacto psicológico da descoberta da infecção, início dos sintomas físicos, progressão da doença e das limitações por ela impostas e as complexas questões psicossociais envolvidas; (2) pode estar diretamente relacionada com a invasão do sistema nervoso central pelo HIV, por infecções oportunistas ou por tumores intracranianos; (3) a infecção, por atingir populações com maior incidência de quadros depressivos (homossexuais e usuários de drogas intravenosas), pode precipitar o quadro em indivíduos predispostos; (4) pode existir uma associação, ao acaso, entre a infecção e a depressão (Maj, 1996).

Atualmente, o transtorno depressivo é reconhecido como um problema de saúde pública em atendimento médico primário, por sua prevalência e por seu impacto no cotidiano de pacientes e familiares envolvidos (Simon et al., 1995). A depressão é uma sensação persistente e constante de que o sujeito não tem valor, o mundo não tem sentido e de que não há esperança para o futuro (Lafer; Amaral, 2000). A depressão se caracteriza por um sentimento de tristeza, desmoralização, solidão, desesperança, inutilidade, desejo de morte, dificuldade para dormir, choro, sentimento de que tudo é inútil, incapacidade de prosseguir vivendo, etc. A sintomatologia depressiva tem alta associação com o pior funcionamento social e a qualidade de vida e maior utilização de recursos de saúde em pacientes de cuidados primários. A intensidade de sintomas depressivos está inversamente relacionada a vários indicadores subjetivos de bem-estar e saúde (Fleck, 2002).

No contexto da soropositividade, o fenômeno da depressão possui características e implicações próprias por influenciar diretamente, dentre outros fatores, a adesão ao tratamento. Segundo Melchior (2000), muitos são os fatores que podem interferir na adesão ao tratamento, dentre os quais se podem destacar as questões relacionadas à saúde mental. O autor afirma que há menor aderência de pessoas com quadros depressivos e ansiedade. Ainda nesse sentido, Malbergier (2001) afirma que um paciente deprimido tende a não aderir ao tratamento, a não tomar as medicações prescritas e a não acatar as orientações médicas, além do risco aumentado de suicídio e, no caso do soropositivo, a experimentar sentimentos de raiva, culpa, autopiedade e ansiedade.

A baixa aderência aos anti-retrovirais pode repercutir negativamente em três dimensões: em relação ao paciente, uma vez que prejudica a resposta à terapêutica e, em conseqüência, à evolução clínica da doença; na equipe de saúde, pois interfere na avaliação dos resultados, gerando frustração e até diminuição do investimento da equipe no paciente, e no sistema de saúde, que pode levar o paciente a submeter-se a procedimentos diagnósticos e terapêuticos desnecessários e de custos elevados (Narciso, Paulilo, 2001).

Diante do exposto, o foco desta pesquisa é a sintomatologia da depressão no contexto da 
soropositividade, tendo como subsídio a teoria das representações sociais, uma vez que esta permite apreender uma riqueza de elementos figurativos dos tipos: cognitivos, ideológicos, normativos, de crenças, valores, atitudes, opiniões, imagens, entre outros. É uma forma de conhecimento prático acerca de uma realidade comum a um grupo social.

As doenças trazem, com elas, alterações e transformações não só no organismo como também no modo de vida e nas relações sociais de um indivíduo. Pesquisar as representações sociais (RS) da depressão no contexto da Aids implica fazer uma leitura não só dos aportes teóricos normativos e científicos mas também do conhecimento elaborado e compartilhado pelo grupo de pertença, procurando perceber como as representações emergem nas relações estabelecidas entre elas e em que medida são determinadas, uma vez que os comportamentos adotados por um indivíduo ou um grupo de indivíduos são resultantes do modo como eles representam socialmente a depressão e do significado pessoal que esta adquire em suas vidas (Coutinho, 2001).

Ciente da relevância do objeto de estudo para o campo da Psicologia social e para ações que atendam aos problemas associados à sintomatologia depressiva no contexto da soropositividade, pretendemos, neste estudo, desenvolver os seguintes objetivos:

- apreender as RS da Aids e da depressão por soropositivos para o HIV;

- avaliar a prevalência da sintomatologia da depressão considerando a importância de se averiguar a influência da sintomatologia na vida dos pacientes.

\section{Método}

\section{Campo de investigação}

Esta pesquisa trata de um estudo de campo ancorado em uma abordagem multimétodo, de cunho qualitativo e quantitativo. O estudo foi desenvolvido em organizações não governamentais (ONGs) e no Hospital Clementino Fraga, todos especializados no atendimento a soropositivos para o HIV, localizados na cidade de João Pessoa - Paraíba.

\section{Participantes}

Participaram deste estudo 91 sujeitos soropositivos, escolhidos aleatoriamente, de forma não-probabilística, intencional e acidental, de ambos os sexos ( $57 \%$ masculino e $43 \%$ feminino), com idade média de 38 anos.

\section{Instrumentos}

Foram utilizados, como instrumentos para coleta dos dados deste estudo: um questionário com os dados sociodemográficos, para melhor caracterização da amostra; o inventário de Beck, para medir depressão BDI (Beck; Steer; Garbin, 1998); e a técnica de associação livre de palavras. Esta última é uma técnica bastante difundida no âmbito da Psicologia social, principalmente quando se trabalha com o suporte teórico/metodológico das representações sociais, uma vez que possibilita acesso aos conteúdos periféricos e latentes (Di Giacomo, 1986; Le Boudec, 1984; De Rosa, 1988; Barros, 2004).

De acordo com Nóbrega e Coutinho (2003), essa técnica projetiva possibilita acesso aos conteúdos formadores de RS sem que ocorra a filtragem da censura à sua evocação. É um instrumento que se apóia sobre um repertório conceitual, com isso permitindo a unificação dos universos semânticos e a saliência de universos de palavras comuns face aos estímulos indutores utilizados no estudo.

Neste estudo, foram utilizados dois estímulos indutores, Aids e depressão, previamente definidos, tendo como pressupostos o objeto investigado bem como os atores sociais que fazem parte da amostra (soropositivos). É válido 
mencionar que, no presente estudo, convencionou-se o tempo máximo de 01 (um) minuto para a evocação das palavras associadas a cada estímulo indutor, perfilando 02 (dois) minutos para cada participante responder o teste de associação livre de palavras.

O inventário de depressão de Beck (BDI), uma escala de auto-avaliação de depressão, foi criado por Aaron T. Beck, da Universidade da Pensylvania (Beck, 1961), e traduzido, no Brasil, por Gorestein e Andrade (1998), tendo se tornado a medida de auto-avaliação de depressão mais amplamente usada tanto em pesquisa quanto na clínica.

O BDI é uma medida da intensidade da depressão, não sendo indicada para identificar categorias nosológicas. Consta de 21 itens, incluindo sintomas e atitudes, cada um com quatro afirmações em graus de intensidade, de 0 a 3. As afirmações são graduadas para refletir a gravidade do sintoma, de neutro (0) até intensidade máxima (3), e as pontuações podem variar de 0 a 63. Os itens são referentes a tristeza, pessimismo, sensação de fracasso, falta de satisfação, sensação de culpa, sensação de punição, autodepreciação, auto-acusações, idéias suicidas, crises de choro, irritabilidade, retração social, indecisão, distorção da imagem corporal, inibição para o trabalho, distúrbio do sono, fadiga, perda de apetite, perda de peso, preocupação somática e diminuição da libido (Calil; Pires, 1998).

Segundo Beck, Steer e Garbin, (1998), a escolha do ponto de corte adequado depende da natureza da amostra e dos objetivos do estudo. Nesta pesquisa, foi adotado o ponto de corte a partir do somatório de 12 pontos, uma vez que o propósito foi o de identificar a presença de sinais indicativos de depressão entre os sujeitos.

\section{Procedimentos}

Inicialmente, solicitou-se a autorização das direções das ONGs, assim como a do Hospital
Clementino Fraga e a dos soropositivos, objetos da pesquisa, para a realização do estudo.

Em seguida, realizou-se um estudo-piloto com o intuito de verificar a boa adequação do instrumento e a validade semântica do mesmo; depois, efetuou-se o estudo definitivo. Foi feita uma apresentação dos pesquisadores aos grupos, aos quais foram explicitados os objetivos do estudo. Foram-lhes garantidos o anonimato e a confiabilidade das respostas, indicando-lhes que seriam analisadas no seu conjunto e, posteriormente, iniciou-se a aplicação dos instrumentos de forma coletiva, respeitando a seguinte ordem: 1) técnica de associação livre de palavras, 2) BDI, e, por fim, o questionário sociodemográfico.

A partir desse prisma, buscou-se compreender e inferir novos conhecimentos acerca da sintomatologia da depressão no contexto da AIDS.

\section{Análise dos dados}

Os dados coletados pela técnica de associação livre foram processados pelo software Tri-DeuxMots (Cibois, 1991), versão 2.2, que permite a visualização gráfica tanto das variáveis fixas (sexo e idade) bem como das variáveis de opinião (conhecimento prático enunciado pelos sujeitos frente aos estímulos indutores), e analisados através da análise fatorial de correspondência (AFC).

O somatório de todas as palavras evocadas (Ó $=947)$ pelo conjunto de sujeitos $(\mathrm{N}=91)$ que compõem a amostra da pesquisa, relativas a cada estímulo indutor (Aids e depressão), são analisadas em função da freqüência e importância relativa às variáveis fixas (sexo e idade), determinando o espaço fatorial ou gráfico.

A AFC é um procedimento estatístico que consiste em distinguir os vínculos estabelecidos entre as características dos indivíduos que constituem um grupo e suas respostas a uma 
determinada questão, ressaltando os vínculos (de aproximação ou distanciamento) existentes entre as representações dos sujeitos e suas qualidades de membros de grupos com características específicas e diferenciadas uns dos outros. O princípio básico da AFC consiste em destacar eixos que explicam as modalidades de respostas, mostrando estruturas constituídas de elementos do campo representacional. Os dados do BDI foram somados para identificar o escore mínimo (12 pontos).

\section{Aspectos éticos}

Este estudo foi realizado considerando-se os aspectos éticos pertinentes a pesquisas envolvendo seres humanos, de acordo com a Resolução no 196/96 sobre Pesquisa Envolvendo Seres Humanos (Brasil: Ministério da Saúde, Conselho Nacional de Saúde, 1996), e foi aprovado pela Comissão de Ética da Universidade Federal da Paraíba (UFPB).

\section{Resultados}

Os resultados coletados por meio do teste de associação livre de palavras, enquanto instrumento de apreensão de significados do conhecimento prático, possibilitaram, com as variáveis fixas, a emersão de campos semânticos sobre a depressão no contexto da soropositividade, conforme pode ser observado no plano fatorial, por meio dos dois fatores nele contemplados (F1 e F2). O gráfico 1 oferece uma representação das variações semânticas na organização do campo espacial, o qual ilustra aproximações e oposições das modalidades na construção dos fatores (F1 e F2). Os dois fatores foram detentores de um poder explicativo de 71,6 \% da variância total de respostas, sendo que o F1 apresentou 40,4 \%, e o F2, 31,2 \%, possuindo, portanto, parâmetros estatísticos com consistência interna e fidedignidade, tendo em vista pesquisas realizadas no âmbito das RS (Nóbrega; Coutinho, 2003).

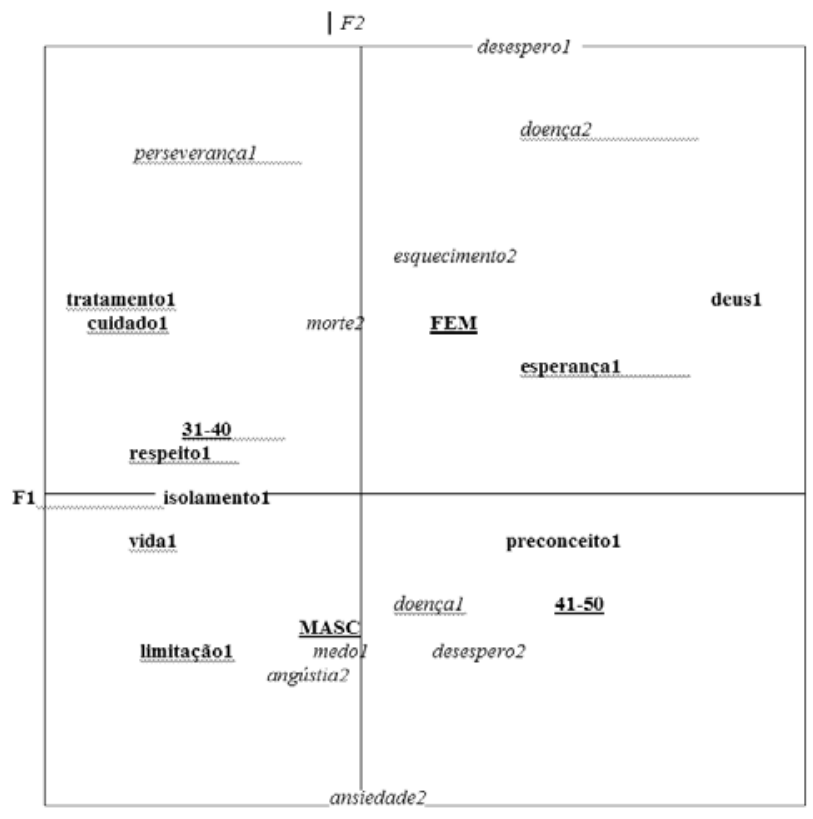

Figura 1: plano fatorial de correspondência das RS da Aids e da depressão 
Observam-se, no gráfico 1, dois campos semânticos configurados em oposição sobre o fator 1. No eixo à esquerda, em negrito, encontram-se aglomeradas as representações acerca da Aids (estímulo1) que caracterizam o grupo dos soropositivos compreendidos na faixa etária entre 31 a 40 anos, de ambos os sexos. Para esse grupo, a Aids é representada como uma doença que causa limitações, fazendo com que as pessoas muitas vezes se isolem, sendo importante haver um respeito para com os soropositivos que lutam pela vida por meio de cuidados e de tratamentos específicos. Inversamente, nesse mesmo fator, à direita, configura-se o campo semântico elaborado pelos soropositivos compreendidos na faixa etária entre 41 a 50 anos, de ambos os sexos. Esses atores sociais associaram a Aids (estímulo1) a uma doença que traz consigo a questão do preconceito, e afirmaram ser preciso haver esperança e um suporte que muitas vezes vem da figura de Deus. Com relação ao fator 2 , linha vertical, os grupos de mulheres e homens encontram-se diametralmente distanciados, o que indica discordâncias representacionais. Na margem superior, em itálico, localizam-se as representações das mulheres acerca da Aids (estímulo1) associadas a uma doença que causa um desespero muito grande, mas que é preciso ter perseverança. Já em relação à depressão (estímulo 2), esse grupo representou-a como uma doença que causa esquecimento e que leva à morte. Na margem inferior, destacam-se as modalidades representacionais dos homens acerca da Aids (estímulo1), configuradas nos elementos: doença e medo. Com relação à depressão (estímulo 2), emergiram os elementos: desespero, angústia e ansiedade.

O inventário de Beck para medir depressão mostrou uma prevalência de $64 \%$ da sintomatologia depressiva, sendo $48 \%$ nas mulheres e $52 \%$ nos homens, ou seja, mais da metade da amostra de ambos os sexos apresentou a sintomatologia da depressão. Destes, 21 (36 \%) apresentaram, segundo Beck, Steer e Garbin (1998), um nível considerado leve de depressão (12 a 19 pontos); 26 (45\%) apresentaram um nível moderado (20 a 35 pontos), e 11 (19\%) apresentaram um nível grave (36 a 63 pontos), como pode ser observado no gráfico 2.

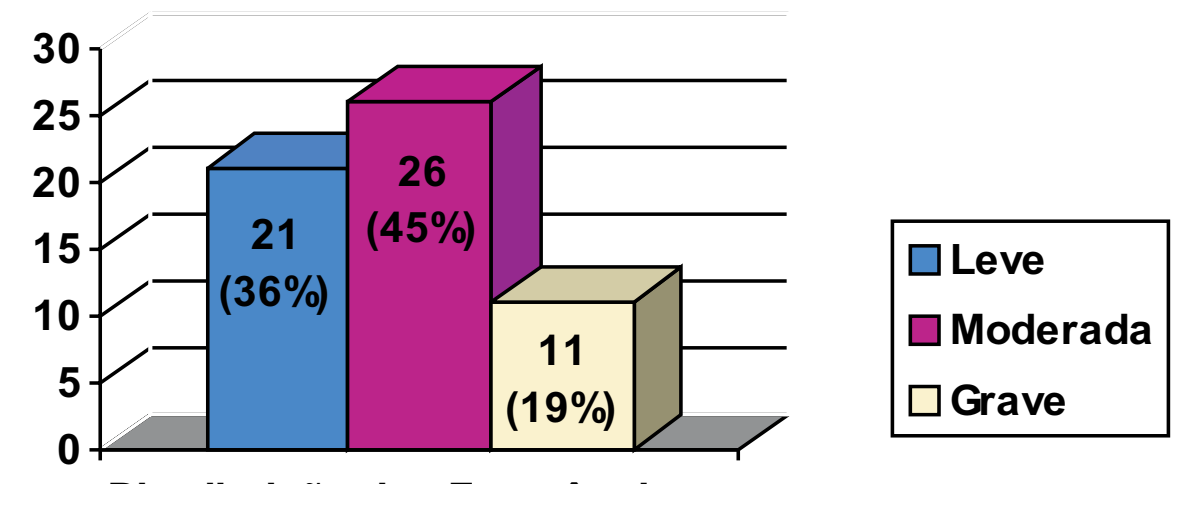

Figura 2 - Distribuição das freqüências e percentuais dos níveis da sintomatologia da depressão

\section{Discussão}

Denotam-se, nos resultados apreendidos por meio da técnica de associação livre de palavras, que as RS dos soropositivos formadas pelo grupo de sujeitos compreendidos na faixa etária de 31 a 40 anos e o grupo de sujeitos compreendidos na faixa etária de 41 a 50 anos estão dimensionadas em dois eixos: Aids, caracterizada pelo predomínio de questões físico-orgânicas, e Aids enquanto predomínio de questões psicossociais, respectivamente. 
No primeiro grupo (31 a 40 anos), há um predomínio de questões físico-orgânicas, no qual os atores sociais representam a Aids como uma doença com toda uma gama de limitações e de cuidados e tratamentos necessários para a manutenção da vida. Surgem, também aí, elementos relacionados ao isolamento.

Apesar de a terapêutica atual ter prolongado a vida dos pacientes infectados e melhorado bastante sua qualidade de vida, viver com Aids impõe várias limitações, entre as quais profissionais e afetivas, dificuldade de manter relacionamentos sexuais, decisão de ter ou não filhos (Malbergier, 2000). A incapacidade trazida pelo adoecimento significa não corresponder às próprias expectativas, às da família e às da sociedade, concorrendo para a frustração e interrupção dos projetos de vida pessoal, familiar e profissional.

Com relação aos cuidados e tratamentos, observa-se que, depois do impacto sofrido pelo diagnóstico, vem a necessidade da reestruturação e manutenção da vida em seus vários papéis. A construção de uma nova identidade após o adoecimento e o retorno à normalidade - que não é saúde - constitui-se num processo dinâmico e complexo, que consiste em assimilar e produzir, de forma ativa, conhecimentos e formas de ação. Com o passar do tempo, a doença é integrada nas esferas da vida como um aspecto a mais, sem que isso implique sua banalização. Trata-se de um tipo de gestão racional da doença, em que as angústias despertadas pelo diagnóstico são canalizadas para as questões do cotidiano (Saldanha, 2001).

No que diz respeito ao isolamento, este é comum entre os portadores, decorrente do medo advindo do estigma social. Manter sigilo parece ser a saída mais adequada (Teixeira, 2000). O auto-isolamento imposto pode resultar na exclusão da vida social e de relacionamentos sexuais e, em circunstâncias extremas, foram relatadas mortes prematuras por meio de suicídio (Gilmore; Somerville, 1994; Malcolm, 1998).

Neste estudo, o primeiro grupo (31 a 40 anos) representou a Aids no aspecto do respeito, que remete à questão do preconceito vivenciado em relação à condição de soropositividade. No segundo grupo (41 a 50 anos), há um predomínio de questões psicossociais, em que os atores sociais representaram a Aids como uma doença que carrega com ela o preconceito e afirmaram que uma das maneiras de enfrentá-la é por meio da esperança e do suporte que pode vir da religiosidade, objetivada na figura de Deus.

Apesar da comprovação científica sobre os meios de transmissão da doença, ainda existe muito medo, preconceito e discriminação em relação aos portadores do HIV /Aids. Moriya (1992) aponta, em seus estudos, alguns dos aspectos associados à Aids, tais como o medo irracional e aspectos psicossociais desfavoráveis evidenciados por desinformações, discriminações e atitudes negativas. O preconceito atinge profundamente os indivíduos, influenciando-os na percepção da própria doença e no comportamento de outras pessoas diante dela.

O preconceito existente em torno da doença faz com que os portadores se tornem carregados de culpa diante do que não podem reverter - culpa que a família, amigos e a sociedade reforçam com cobranças, discriminação, isolamento e omissão. Dessa maneira, contrair o vírus HIV implica uma transgressão que favorece, por sua vez, uma estereotipia de acusações e culpa de caráter individualizado, cujos comportamentos são representados como ameaças à sociedade por serem portadores de uma doença tão temida. Esses comportamentos seriam a conseqüência de um comportamento sancionado negativamente por certos grupos da sociedade como forma de punição moral pelo pecado (Martin, 1995).
A incapacidade trazida pelo adoecimento significa não corresponder às próprias expectativas, às da família e às da sociedade, concorrendo para a frustração e interrupção dos projetos de vida pessoal, familiar e profissional. 
Com relação à esperança e à religião, esta última surge como apoio, representando uma importante rede de suporte emocional. Saldanha (2001) observou, em mulheres soropositivas, um aumento, após a contaminação, da procura pela religião, através da qual alegaram receber grande conforto e esperança de cura. A autora afirma, ainda, que, desde que as crenças não se tornem exacerbadas, prejudicando ou interrompendo o tratamento, a fé e a esperança de cura contribuem para uma melhora no quadro geral das pacientes.

Muitos estudos abordam as diferentes estratégias pelas quais as religiões reinterpretam a experiência da doença e modificam a maneira pela qual o doente e o meio social definem o problema. Para LéviStrauss (1967), as teorias religiosas curam ao impor ordem sobre a experiência caótica do doente e da família. Segundo Gir (1997), as religiões são criadas como uma estrutura para um sistema de crenças, valores, códigos de condutas e rituais e apresentam os componentes de fé, ou crença, esperança e amor. $\mathrm{O}$ indivíduo que tem crenças religiosas sente em si mais força, seja para suportar as dificuldades da existência, seja para vencêlas. Dessa maneira, os soropositivos encontram, na crença religiosa, um grande auxílio para suportar as privações e angústias impostas pela doença.

Observa-se, por meio desses dados, que os dois grupos possuem representações similares no que diz respeito ao preconceito, e, dessa maneira, este pode ser considerado como o elemento supostamente central no campo das RS da Aids (Abric, 1998) ou o elemento figurativo da representação (Moscovici, 1981). Percebem-se, também, alguns elementos distintos entre esses dois grupos, como limitações, cuidados, tratamentos (31 a 40 anos) e esperança e Deus (41 a 50 anos).

Com relação ao grupo das mulheres, independentemente da faixa etária, ele representou a Aids como uma doença que causa desespero, sendo necessário ter perseverança para continuar a viver. Já os homens representaram a Aids como uma doença que causa medo.

As mulheres, assim como os homens, retrataram, aqui, a questão do sofrimento decorrente da soropositividade. O sofrimento causado pela Aids pode ser proveniente de diversos fatores, dentre os quais podemos destacar: o diagnóstico, o processo do adoecimento, a iminência de morte, a discriminação, as limitações e as perdas.

As formas de conhecimento produzidas sobre a Aids, neste e em outros estudos, têm uma conotação de doença, traduzida por angústia, pânico, rejeição, cujas interpretações de cunhagem são ainda de ordem primitiva (Silva,2003; Herzlich; Pierret,1992; Martin,1995). Apesar da evolução terapêutica e de seu reflexo direto na reinterpretação da Aids, observa-se, ainda hoje, que ela continua sendo associada à morte e ao sofrimento.

A morte causada por uma doença incurável está nitidamente apresentada como elemento do núcleo central das representações sociais da Aids e é organizadora de várias cognições. A Morte é vista como terrível, premeditada, lenta, mobiliza o medo e discrimina o outro que não se previne (Tura, 1998).

Ainda em relação aos grupos das mulheres e dos homens, percebe-se que a depressão foi representada em duas esferas, depressão ancorada na esfera físico-orgânica e depressão ancorada na esfera psicoafetiva.

No grupo das mulheres, independentemente da faixa etária, a depressão foi representada como uma doença que causa esquecimento e que leva à morte. Observa-se, aqui, um predomínio da esfera físico-orgânica relacionada a manifestações cognitivas, tais como a falta de concentração e esquecimento, assim como a questão da morte, que, no 
contexto da depressão, está muitas vezes atrelada ao suicídio.

A depressão pode ser proveniente de uma reação de ajustamento psicológico, precipitando sintomas como fadiga, dificuldade de concentração, prejuízo de memória, apatia, ansiedade, hipocondria e diminuição da libido. Entretanto, a intensidade dos sintomas é muito variável, de acordo com a capacidade do indivíduo de lidar com o estresse (Malbergier; Panutti, 1993).

No grupo dos homens, a depressão foi representada através da esfera psicoafetiva e é vista como sinônimo de angústia, ansiedade e desespero.

Com relação aos sentimentos nos quais a depressão foi ancorada, Malbergier (2001) afirma que o soropositivo experimenta sentimentos de raiva, culpa, autopiedade e ansiedade. A baixa auto-estima e, principalmente, o abandono por parte dos familiares e amigos podem levar a tentativas de suicídio.

A capacidade de ajustamento psicológico às mudanças, segundo Ferreira e Abreu (1988), influencia no desencadeamento de sintomas e mecanismos defensivos, como, por exemplo, a ansiedade decorrente das alterações físicas e do tratamento. São praticamente inevitáveis sintomas depressivos (tristeza, desamparo, diminuição da autoestima).

Os resultados coletados por meio do inventário de Beck para medir depressão (BDI) não corroboraram a literatura em relação aos índices encontrados de prevalência da sintomatologia depressiva no contexto da Aids, que varia de 11 a 30 \% (Rodin; Craven; Littlefield, 1991). Foi encontrado, neste estudo, um índice bem maior (64\%), que pode ser explicado pelo fato de a sintomatologia estar sendo subdiagnosticada, corroborando estudos realizados por Malbergier (2001), nos quais ele afirma que 50 a $60 \%$ dos casos de depressão não são diagnosticados. Esses dados corroboraram também o teste de associação livre de palavras, no qual fica evidente a presença e importância da sintomatologia na vida dos soropositivos.

\section{Considerações finais}

As representações sociais apreendidas neste estudo abarcaram aspectos biológicos e psicossociais, revelando uma similitude com o conhecimeto científico no que diz respeito às temáticas da Aids e da depressão. Percebese que há uma ligação forte entre essas duas temáticas quando surgem, nos dados, elementos que estão próximos e até presentes em ambas, tais como os elementos de desespero, medo, angústia, doença e morte.

Um outro elemento bastante forte presente nas representações sociais foi o do preconceito, que é um dos principais desencadeadores da sintomatologia depressiva no contexto da Aids, uma vez que implica abandono, segregação, estigmatização e ruptura nas relações pessoais quando o apoio se torna imprescindível.

Os sujeitos representaram a depressão e a Aids como uma doença que atinge o ser humano em sua globalidade, repercutindo em vários aspectos de sua vida, tais como na qualidade de vida, na produtividade e na incapacitação social. Observou-se também que a Aids foi ancorada nas doenças psicoafetivas, nomeadamente na depressão, o que corrobora o alto índice de prevalência da sintomatologia depressiva encontrada neste estudo (64\%).

A prevalência da sintomatologia depressiva encontrada remete à necessidade do preparo dos profissionais para diagnosticarem o fenômeno dentro de um contexto não só da Aids mas das doenças clínicas em geral. O profissional que é treinado somente para procurar a doença orgânica está fadado a vêla e a perder as nuanças e dramas da 
experiência humana, enfatizando mais a doença do que os pacientes que dela sofrem.

O tratamento da depressão associada a uma doença clínica, como no caso da Aids, é importante não só porque o transtorno afetivo pode comprometer a qualidade de vida mas também porque a intervenção psiquiátrica nesse contexto pode reduzir uma utilização desnecessária dos cuidados de saúde, diminuir a mortalidade e prolongar a sobrevida do paciente (Wells et al., 1989).
Diante desses dados, evidencia-se a necessidade de se entender os fatores associados e os determinantes da depressão no contexto da Aids, e, dessa maneira, incrementar estratégias de intervenção nos serviços de saúde que levem em consideração o fenômeno como um dos fatores que influenciam diretamente a vida de soropositivos, nomeadamente, na adesão ao tratamento e na qualidade de vida como um todo.

Alessandra Ramos Castanha

Psicóloga. Mestre em Psicologia Social - Universidade Federal da Paraíba

Maria da Penha de Lima Coutinho

Doutora em Psicologia. Departamento de Psicologia - Universidade Federal da Paraíba.

Ana Alayde Werba Saldanha

Doutora em Psicologia. Departamento de Psicologia - Universidade Federal da Paraíba.

Cristiane Galvão Ribeiro

Psicóloga. Mestranda em Psicologia Social - Universidade Federal da Paraíba

\section{Alessandra Ramos Castanha}

Rua Bernardo Gabriel, 88 - Apto.101- Imbiribeira

Recife-PE. Cep: 51.170-380 Fone/Fax: (81) 3339-0974

E-mail: alecas@bol.com.br 
ABRIC, J. C. A Abordagem Estrutural das Representações Sociais. In M. A. S. P. Moreira; D. C. Oliveira (orgs.). Estudos Interdisciplinares de Representações Sociais. Goiânia: AB, 1998, pp.59-82.

BARROS, D. R. Representaçóes Sociais de Profissionais das Áreas de Humanas e da Saúde acerca do Alcoolismo. Dissertação de Mestrado em Psicologia Social. Universidade Federal da Paraíba, João Pessoa-PB, 2004.

BECK, A. T. Inventory for Measuring Depression. Archives of General Psychiatry, 4. Chicago, 1961, pp.561-571.

BECKA. T.; STEER R. A.; GARBIN M. G. Psychometric Properties of the Beck Depression Inventory: Twenty-five Years of Evaluation. Clinical Psychology Review, Baltimore, 1998.

BRASIL M. A. Comorbidade - Depressão e Doenças Clínicas. Revista Depressão e Comorbidades. São Paulo: Edição Única, 1999, pp.3743.

CALIL, H. M.; PIRES, M. L. N.; Aspectos Gerais das Escalas de Avaliação da Depressão. Rev. Psiq. Clín. v. 25, n.5. São Paulo, 1998 , pp. 240244. Edição Especial.

CIBOIS, P. L'Analyse Factorielle. Paris: Puf, Collecion "Que sais-je?" $3^{a}$ ed, 1991.

COUTINHO, M.P.L. Depressão Infantil: uma Abordagem Psicossocial. João Pessoa: Editora Universitária/Autor Associado, 2001.

DE ROSA, A. S. Sur l'Usage des Associations Libres dans l'Étude des Représentations Sociales de la Maladie Mentale. Connexions, $\mathbf{n}^{\circ} 51$. Papeteries Hamelin, 1988, pp.27-50.

DI GIACOMO, J. P. Alliances et Rejets Intergroupes au Sein dun Movement de Revendication. In W. Doise; A. Palmonari (orgs.). L'Étude des Représentations Sociales. Paris: Delchaux; Niestle, 1986, pp. 118-138.

FERREIRA P.E.; ABREU P.B. Aspectos Psicológicos da Aids. Revista ABPAPAL, v.10, n.2. São Paulo, 1988, pp. 42-6.

FLECK, M. A. Associação entre Sintomas Depressivos e Funcionamento Social em Cuidados Primários à Saúde. Rev. Saúde Pública, v.36, n.4 . São Paulo, 2002, pp.431-438.

GILMORE N.; SOMERVILLEM.A. Stigmatization, Scapegoating and Discrimination in Sexually Transmitted Diseases, Overcoming "them" and "us". Social Science and Medicine, 39. Leicester, 1994, pp.1339-1358.

GIR, E. A Sexualidade e a Mulher Portadora do Vírus da Imunodeficiência Humana Tipo 1 (HIV-1). Tese de Doutorado. Escola de Enfermagem de Ribeirão Preto - USP, 1997.

GORENSTEIN, C.; ANDRADE, L.; Inventário de Depressão de Beck: Propriedades Psicométricas da Versão em Português. Rev. Psq. Clín. v.25,n.5. São Paulo, 1998, pp. 245-250.

HERLIZCH C.; PIERRET J. Uma Doença no Espaço Público: a Aids em seis Jornais Franceses. Physis: Rev. Saúde Coletiva, v.2, n.1. Rio de Janeiro: 1992, pp.7-35.

LAFER B.; AMARAL J.A. Depressão no Ciclo da Vida. Porto Alegre: Artes Médicas; 2000.

LE BOUDEC, G. Contribution à la Méthodologie d'Étude des Représentations Sociales. Cahiers de Psycologie Cognitive, 4. Montreal, 1984, pp.245-272.

LÉVI-STRAUSS. Antropologia Estrutural. 2ª edição, Rio de Janeiro: Tempo Brasileiro, 1967.

MAJ M. Depressive Syndromes and Symptoms in Subjects with Human Immunodeficiency Virus (HIV) Infection. British Journal of Psychiatry, 168, Supplement 30. Leeds, 1996, pp.117-22.
MALCOLM A. HIV and AIDS-Related Stigmatization and Discrimination: its Form and Contexts. Critical Public Health, 8 (4). Middlesbrough, 1998, pp.347-370.

MALBERGIER A. Aids e Psiquiatria - um Guia para os Profissionais de Saúde. Rio de Janeiro: Revinter, 2000.

MALBERGIER A.; PANNUTI D. Alterações Psicopatológicas em Indivíduos Infectados pelo Vírus da AIDS: Revisão da Literatura. Revista ABP-APAL 15. São Paulo, 1993, pp.128-34.

MALBERGIER A.; SCHOFFEL A. C. Tratamento de Depressão em Indivíduos Infectados pelo HIV. Rer. Bras. Psiquiatr., 23(3). São Paulo, 2001, pp.160-7.

MARTIN D. Mulheres e Aids: uma Abordagem Antropológica. Dissertação de Mestrado. Universidade de São Paulo, São Paulo, 1995.

MELCHIOR, R. Avaliação da Aderência dos Usuários do Sistema Público de Assistência ao Tratamento de Aids: uma Análise Qualitativa. Dissertação de Mestrado. Faculdade de Saúde Pública da Universidade de São Paulo, São Paulo, 2000.

MORIYA T. H. Escala de Atitudes frente à AIDS: uma Análise Psicométrica. Tese de Doutorado. Escola de Enfermagem de Ribeirão Preto - USP, Ribeirão Preto, 1992.

MOSCOVICl, S. La Psychanalyse, son Image et son Public. Paris: Press Universitaires de France, 1981.

NARCISO, A. M. S, PAULILO, M. A. S. Adesão e AIDS: alguns Fatores Intervenientes. Serviço Social em Revista, v.4, n.1. Londrina, 2001.

NÓBREGA, S. M.; COUTINHO, M. P. L. O Teste de Associação Livre de Palavras. In Coutinho, M. P. L. (org.). Representações Sociais: Abordagem Interdisciplinar. João Pessoa: EdUFPB, 2003, pp. 67-77.

RODIN, G.; CRAVEN, J; LITTLEFIELD, C. Depression in the Medically ill. New York: Brunner/Mazel, 1991.

SALDANHA, A. A. W. Vulnerabilidade e Construções de Enfrentamento da Soropositividade ao HIV por Mulheres Infectadas em Relacionamento Estável. Tese de Doutorado. Faculdade de Filosofia, Ciências e Letras de Ribeirão Preto, Universidade de São Paulo, Ribeirão Preto, SP, 2003.

SILVA, A. O. Utilização da Teoria das Representações Sociais no Campo da Saúde. UFPB-João Pessoa: Tendências e Perspectivas. In Coutinho, M. P. L.; Lima, A. S; Oliveira, F. B.; Fortunato, M. L. (orgs.). Representações Sociais: Abordagem Interdisciplinar. João Pessoa: Editora Universitária/UFPB, 2003, pp.120-129.

SIMON, G.; ORMELL, J.; VONKORFF, M.; BARLOW, W. Health Care Costs Associated with Depressive and Anxiety Disorders in Primary Care. Am. J. Psychiatry, 152. Arlington, 1995, pp.352-7.

TEIXEIRA P. R. Tá Difícil de Engolir? Experiências de Adesão ao Tratamento Anti-retroviral em São Paulo. São Paulo: Nepaids, 2000.

TURA, L. F. R. AIDS e Estudantes: a Estrutura das Representações Sociais. In Jodelet, D. e Madeira, M. (org.). AIDS e Representações Sociais: a Busca de Sentidos. Natal: EDUFRN, 1998, pp.121-154.

WELLS, K. B.; STEWART, A.; HAYS, R. D.; BURNAM, M. A.; ROGERS, W.; DANIELS, M. The Functioning and Well-being of Depressed Patients. JAMA, 262. Chicago, 1989, pp. 914-19.

\section{Referências}

